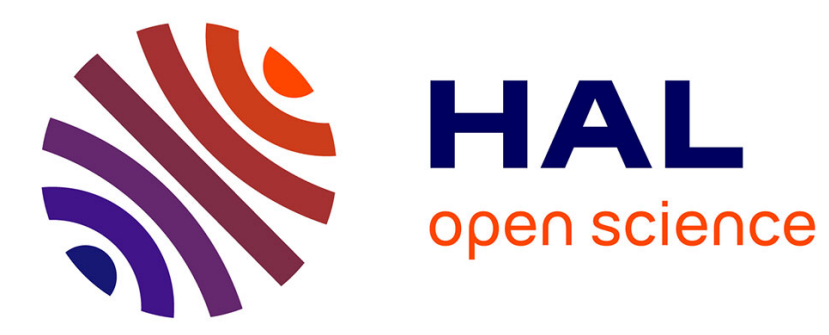

\title{
Ionic Liquids and their hosting by polymers for HT-PEMFC membranes
}

\author{
Jean-Yves Sanchez
}

\section{To cite this version:}

Jean-Yves Sanchez. Ionic Liquids and their hosting by polymers for HT-PEMFC membranes. Fuel Cells, 2010, 10 (5), pp.778. 10.1002/fuce.201000026 . hal-00578452

\section{HAL Id: hal-00578452 \\ https://hal.science/hal-00578452}

Submitted on 21 Mar 2011

HAL is a multi-disciplinary open access archive for the deposit and dissemination of scientific research documents, whether they are published or not. The documents may come from teaching and research institutions in France or abroad, or from public or private research centers.
L'archive ouverte pluridisciplinaire HAL, est destinée au dépôt et à la diffusion de documents scientifiques de niveau recherche, publiés ou non, émanant des établissements d'enseignement et de recherche français ou étrangers, des laboratoires publics ou privés. 


\section{Ionic Liquids and their hosting by polymers for HT-PEMFC membranes}

\begin{tabular}{|c|c|}
\hline Journal: & Fuel Cells \\
\hline Manuscript ID: & fuce. $201000026 . R 1$ \\
\hline Wiley - Manuscript type: & Original Research Paper \\
\hline $\begin{array}{r}\text { Date Submitted by the } \\
\text { Author: }\end{array}$ & 02-Apr-2010 \\
\hline Complete List of Authors: & $\begin{array}{l}\text { sanchez, jean-yves; LEPMI, PHELMA, Grenoble Institute of } \\
\text { Technology }\end{array}$ \\
\hline Keywords: & $\begin{array}{l}\text { Polymer Electrolyte Membrane Fuel Cell, Polymer Electrolyte } \\
\text { Membrane, Ionic Conductivity, High Temperature, Membrane, PEM } \\
\text { Fuel Cell }\end{array}$ \\
\hline
\end{tabular}

\section{S) ScholaronE \\ Manuscript Central}


Referee(s)' Comments to Author:

Reviewer: 1

Comments to the Author

The manuscript is interesting and well-written. Thus, I recommend its publication as is.

\section{Reviewer: 2}

Comments to the Author

This manuscript describes properties of many protic ionic liquids as electrolyte for fuel cell. Overall, I feel a lack of comprehensive review and citation of the relating previous studies. As this paper, which is not intended to be a review, includes already 31 references, we added only one reference that is a review dealing with the proton-conducting ionic liquids.

Although the authors aims at the applying these protic ionic liquids and their composite membranes to fuel cells, there are no data about fuel cell reactions (HOR and ORR) and also fuel cell performances. These are my major comments. I would conclude that this paper needs major revision by addressing these major comments and the following detailed comments.

We performed ORR investigation and we have available some data. In this topic a wide variety of Ionic Liquids has however been prepared and characterized by several academic laboratories. The purpose of this paper was, by selecting a limited number of ionic liquids, to get a better understanding of the relations between conductivity, transference numbers, viscosity, humidity that govern the performances of ionic liquids. In addition as the latter are liquids a particular attention has been paid to the ionic liquid/host polymer interactions that are essential as they govern the membrane performances. Therefore the selected approach was to focus on material science aspects (physical-chemistry, mechanic etc.)to validate whether such blends can meet the requirements to be operated at high temperature and in poorly humidified conditions (in terms of conductivity and thermomechanical performances). Thus, inclusion of our preliminary ORR tests, in this manuscript would be harmful to the homogeneity and the balance of the paper. [However I send to the reviewer the ORR result, which I repeat deals with preliminary results]

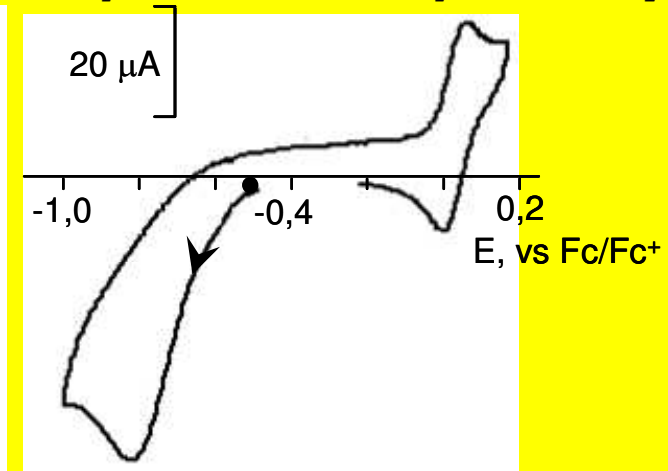

Cyclic voltammogram of $\mathrm{O}_{2}$ saturated TEATf on vitreous carbon disk electrode $(3 \mathrm{~mm}$ diameter), scan rate $=100 \mathrm{mVs}^{-1}, \mathrm{~T}=50^{\circ} \mathrm{C}$. Internal redox reference: ferrocene

1. The properties of certain protic ionic liquids, which the authors report in this paper, have already reported in literatures. The authors should refer to these papers and also need to address the similarity or the difference of the data.

Some of the results were previously published by our group (some of them from 2006, ISPE-10 lecture) and the others by other groups. As the PCILs 
properties drastically depend on their purity, their water content, and the characterization techniques used, we selected, in order to get a more accurate comparison, to refer to data obtained in the same conditions.

2. The authors claim that a change in Tm of cyclic ammonium PCILs can be explained by their geometry and flexibility. However, cyclopentane shows much lower Tm than cyclohexane. Similarly, pyrrolidine shows much lower Tm than piperidine. I would like to know the authors' opinion about the difference between PCIL and neutral molecules?"

In cyclopentane the medium angle (108\%) according to a planar structure leads, in cycloalkane serie, to the lowest Pitzer angle tension ($\left.0.75^{\circ}\right)$ while the medium angle in cyclohexane $\left(120^{\circ}\right)$ exceeds the tetrahedric angle $\left(109^{\circ} .5\right)$ leading with the same assumption to a Pitzer tension of + $5.5^{\circ}$. But from calorimetric measurements cyclohexane appears as the most stable cycloalkane. To explain this discrepancy it was proposed that cyclopentane has several non-planar conformations and in particular the envelop one. The same explanation was provided for cyclohexane with a variety of conformations and the well-known chair-boat equilibrium. When the methylene group is changed into an ammonium the medium angle should change as well as the ring tension and therefore impact on the planarity deformation. The reviewer remark is excellent but honestly, despite these assumptions, we cannot provide, as we did not perform X-Ray investigation, sounder explanations.

3. Was sulfonated poly (ether sulfone) synthesized? If so, the molecular characterization is required. If not, the supplier should be given.

The reviewer is right. The sulfonation process and characterisation of sulfonated polysulfones were already reported in references [23, 24]. In experimental part we therefore include these references.

4. Is the unit of $Y$ axis in Figure 8 correct?

Many thanks to the reviewer: we did a big mistake (factor 106!!). It has been corrected

5. There are many typographical errors.

Grotthus >> Grotthuss

It was modified

Bronsted >> Brønsted

It was modified

trifluoromethylsulfonic acid >> trifluoromethanesulfonic acid (page 10 line 14)

voltametry >> voltammetry (page 17 line 13)

They have been modified 


\title{
Ionic Liquids and their hosting by polymers for HT-PEMFC membranes.
}

\author{
C.Iojoiu* $^{1}$, H.Maha ${ }^{1}$, Y.Molmeret ${ }^{2}$, M.Martinez ${ }^{1}$, L.Cointeaux ${ }^{1}$, N.El Kissi ${ }^{2}$, Joao Teles ${ }^{3}$, J- \\ C.Leprêtre ${ }^{1}$, P.Judeinstein ${ }^{3}$, J-Y.Sanchez ${ }^{* 1}$
}

1. LEPMI-ELSA, PHELMA, Grenoble Institute of Technology, BP.75, 1130 rue de la Piscine, 38402 Saint-Martin-d'Hères cedex, France.

2. Laboratoire de Rhe'ologie, UMR 5520 CNRS-INPG-UJF, ENSHMG, BP 53, 38041, Grenoble, France.

3. Institut de Chimie Moléculaire et des Matériaux, CNRS 8182, Bâtiment 410, Université Paris-Sud 11, 91405 Orsay Cedex, France.

* Christina.Iojoiu@lepmi.grenoble-inp.fr

* Jean-Yves.Sanchez@lepmi.grenoble-inp.fr

\begin{abstract}
:
The paper deals with proton-conducting ionic liquids (PCILs) for use, in combination with functional polymers, in membranes operating in High Temperature PEMFC. Monoammoniums derived from monoamines and half-neutralized diamines were investigated in the form of triflates. Promising results were obtained with the half-neutralized diaminebased PCIL, its conduction being governed by both Grotthuss-like and vehicular mechanisms, the respective contributions of which depend on temperature. In addition, their blending with Nafion results in a distinct reinforcement of the membrane.
\end{abstract}

Keywords: Fuel cells, Proton-conducting Ionic Liquids, membranes, PFG-NMR. 


\section{Introduction}

Along with ensuring the availability of sufficient drinking water and food resources, finding new energy sources to provide alternatives to current sources based on fossil fuels is perhaps one of the main scientific and technological challenges facing human society in the present century. Indeed, in addition to the scarcity of oil resources, albeit temporarily alleviated by recent discoveries, pollution concerns make it indispensable to seek alternative energies e.g. photovoltaic and wind turbines, both requiring electrochemical storage sources to smooth the peaks in electricity production. Not only must the production of greenhouse gases, such as the renowned $\mathrm{CO}_{2}$, be drastically decreased but so too must emissions of a variety of chemical pollutants by gasoline- and diesel-powered internal combustion engines. In addition to their role in smoothing electricity production by solar plants and wind turbines (batteries, supercapacitors), advanced electrochemical energy sources can increasingly be used by themselves in automotive and electricity implementations.

Heat electricity cogeneration and tri-generation can be achieved using Fuel Cells, namely SOFCs (Solid Oxide Fuel Cells) or PEMFCs (Proton Exchange membrane Fuel Cells). Although the SOFC has a high operating temperature, which is an asset for this implementation, the PEMFC is also considered. Heat recovery will nevertheless be markedly improved by increasing the operating temperature of PEFMCs, currently around $80^{\circ} \mathrm{C}$. The reliability target of PEMFC units dedicated to stationary applications was 20,000 hours in 2005 and it is planned to increase this to 90,000 hours by 2020 . The cost per $\mathrm{kW}$ should decrease from 2005 to 2020 by a factor of 20 ! Both reliability and cost targets are stiff challenges.

The other promising implementation of electrochemical sources concerns automobiles. Moving from cars powered by gasoline and diesel internal combustion engines to electric EV and hybrid HEV \& PHEV cars would make a significant contribution to decreasing urban 
pollution. While current hybrid cars like the Toyota Prius are partly powered by Nickel-Metal Hydride batteries, car manufacturers are looking for more efficient energy sources. There are two main options, lithium batteries and PEMFCs. Lithium batteries, thanks to their higher energy and power densities, appear attractive provided that they meet the implementation requirements in terms of both safety and cost per kWh. The other option, using PEMFCs, needs to find a solution to the recharge time issue. A third option involves hybridizing lithium batteries and PEMFCs. Indeed, Nissan and PSA have already built EV prototypes associating lithium-ion batteries and PEMFCs. Once again, an increase in the operating temperature of PEMFCs from $80^{\circ}$ to at least $120^{\circ} \mathrm{C}$ would suit most car manufacturers as it would help overcome one of the main issues relating to heat management in EV. Indeed, the electrical yield of PEFMC is close to $50 \%$ and removal of the heat produced cannot be achieved with current car radiators, at least in small to medium cars. In addition, increasing the operating temperature will benefit PEMFCs as it will increase the tolerance of electrocatalysts to carbon monoxide poisoning. Increasing the operating temperature of PEMFCs to $120^{\circ} \mathrm{C}$ requires that high proton conductivities be maintained.

Membrane conductivities are mainly governed by their water uptake. Given that the solution of pressurizing PEMFCs is generally excluded, current membranes must be replaced by new membranes exhibiting high proton conductivities at the anhydrous state. The composite approach involving the filling of ionomers with inorganic fillers that exhibit intrinsic high proton conductivity, such as phosphatoantimonic acids, improves the conductivities of various ionomers, in particular above $80^{\circ} \mathrm{C}$, but it is unsuitable for operations at $\mathrm{T} \geq 120^{\circ} \mathrm{C}[1,2]$. Another approach deals with the use of polymer-acid complexes. Although anhydrous complexes between poly(oxyethylene) and phosphoric acid allow reaching conductivities $\geq 1 \mathrm{mS} / \mathrm{cm}$ around $80^{\circ} \mathrm{C}$, they would be unstable in a PEMFC [3]. Other complexes obtained from $\operatorname{poly}(\gamma$ aminopropylsiloxane), partly neutralized by triflic 
acids, reached conductivities as high as $10 \mathrm{mS} / \mathrm{cm}$ at $120^{\circ} \mathrm{C}$, [4] but once again the chemical stability of the host polymer, in a PEMFC, seems questionable.

Complexes based on high-performance thermostable polymers could overcome the chemical issues related to the previous polymer complexes. Thus polybenzimidazole PBI, blended to phosphoric acid $\mathrm{H}_{3} \mathrm{PO}_{4}$ has been proposed as a promising membrane for High Temperature PEMFCs [5,6] (HT-PEMFC). The monomer repeat unit of PBI is a fairly weak Lewis base that favours interaction with the acidic proton of phosphoric acid. The decisive parameter for obtaining highly conductive $\mathrm{PBI} / \mathrm{H}_{3} \mathrm{PO}_{4}$ membranes is the phosphoric acid uptake [6]. An increase in $\mathrm{H}_{3} \mathrm{PO}_{4}$ doping levels results in a clear increase in membrane conductivity related to the increase in proton "carriers". Thus at $150^{\circ} \mathrm{C}$, for $\mathrm{H}_{3} \mathrm{PO}_{4}$ doping levels of molarities 4.7, 6.7 and 14.5, respective conductivities of 18,22 and $79 \mathrm{mS} \mathrm{cm}^{-1}$ were obtained. The huge acid excess, however, results in dramatic degradation in both the membrane (mechanical properties) and the electrodes [7]. A clear performance degradation [7] was reported after a lifespan test of $\sim 550 \mathrm{~h}(500 \mathrm{~h}$ continuous operation and $50 \mathrm{~h}$ intermittent), performed in dry conditions, at $150^{\circ} \mathrm{C}$, on a $\mathrm{H}_{3} \mathrm{PO}_{4} / \mathrm{PBI}$-based PEMFC. Despite their drawbacks, $\mathrm{H}_{3} \mathrm{PO}_{4} / \mathrm{PBI}$ membranes have given rise to a worldwide research effort that should lead to an improvement in performance and lifespan, making PBI-based membranes one of the most relevant routes to achieving High Temperature PEMFC.

An attractive alternative to phosphoric acid involves using proton-conducting ionic liquids (PCILs). Previous studies carried out, in particular by the laboratories of M. Watanabe [8-12] and A. Angell [13-15], have emphasized the high potential of these organic ionic liquids. Many data were published on PCIL, most of them been gathered in the review of Greaves et al. [16]. Nevertheless, these liquid salts must be embedded in a polymer to meet the requirements of PEMFC membranes in terms of thickness and safety. This contribution aims, through a multidisciplinary approach, to provide an overview of the impact of the 
structure of PCILs on their thermal, electrochemical and conductive behaviour. Special attention has been paid to membrane performance and, in particular, to the relationship between conductivity and mechanical stability. Although a huge variety of PCILs can be envisaged by combining various anions and ammoniums, this paper does not intend to be exhaustive. We have therefore decided to keep the same anion, i.e. triflate, and to vary the ammoniums.

\section{Experimental part}

$\underline{\text { Proton-conducting ionic liquid (PCIL) syntheses }}$

The PCIL syntheses were performed following the protocol described in previous publication $[17-21]$

PCIL water content was checked by Karl Fisher measurements and for all PCILs it was lower than $50 \mathrm{ppm}$.

PCIL purity was then checked by NMR, using a Bruker WM 250 spectrometer operating at frequencies of $250 \mathrm{MHz}$ for the ${ }^{1} \mathrm{H}$ and $235.3 \mathrm{MHz}$ for ${ }^{19} \mathrm{~F}$. The samples were dissolved in $\mathrm{CDCl}_{3}$. Peak assignments of PCILs were carried out by reference to the starting amines and acids.

\section{Cyclic voltammetry}

All electrochemical measurements were made under an argon atmosphere in a dry glove box. Cyclic voltammetry (CV) experiments were performed using an Autolab potentiostat/ galvanostat in $\mathrm{CH}_{3} \mathrm{CN}+0.1 \mathrm{M} \mathrm{Bu} \mathrm{Bu}_{4} \mathrm{NClO}_{4}$ (TBAP). The standard three-electrode electrochemical cell was used. The reference electrode was $\mathrm{Ag}$ wire/0.01 $\mathrm{M} \mathrm{AgNO}$ in $\mathrm{CH}_{3} \mathrm{CN}$ $0.1 \mathrm{M} \mathrm{Bu}_{4} \mathrm{NClO}_{4}$. Potentials can be converted to the SHE (Standard Hydrogen Electrode) system by adding $0.548 \mathrm{~V}$ [22]. The working electrode ( $5 \mathrm{~mm}$ in diameter) was a platinum disk polished with $2 \mu \mathrm{m}$ diamond paste (Mecaprex Presi). Thanks to this protocol, it was possible to 
compare, at room temperature $\left(\sim 30^{\circ} \mathrm{C}\right)$, the electrochemical behavior of the all PCILs. Cyclic voltammetry allowed Epa (anodic peak potential), Epc (cathodic peak potential) and for reversible processes $\mathrm{E}_{1 / 2}(=(\mathrm{Epa}+\mathrm{Epc}) / 2)$ and $\Delta \mathrm{Ep}(=\mathrm{Epa}-\mathrm{Epc})$ to be determined. Some experiments were however performed in pure ionic liquid (for PCIL's exhibiting melting points fairly low). In that case, the $\mathrm{Ag}^{+} / \mathrm{Ag}$ reference electrode was separated from the PCIL by an intermediary compartment containing the same PCIL. This device was checked using ferrocene $\left(\mathrm{E}_{1 / 2}=0.09 \mathrm{~V} / \mathrm{Ag}^{+} / \mathrm{Ag}\right)$. It should be added that, both methods (pure PCIL or $\mathrm{CH}_{3} \mathrm{CN}$ solution), led to close electrochemical behavior of the PCIL.

\section{$\underline{\text { Thermal analysis }}$}

Glass transition temperatures, $\mathrm{T}_{\mathrm{g}}$, melting temperatures, $\mathrm{T}_{\mathrm{m}}$, and crystallization temperature, $\mathrm{T}_{\mathrm{c}}$, were measured in nitrogen flow using a TA Instruments DSC 2920 modulated DSC. Around $10 \mathrm{mg}$ of the sample was placed in a DSC aluminium crucible in a glove box. In a typical procedure, the samples were cooled rapidly to $-100^{\circ} \mathrm{C}$ and then heated at a rate of $5^{\circ} \mathrm{C} . \mathrm{min}^{-1}$ up to $200^{\circ} \mathrm{C}$. The oscillation period was $60 \mathrm{~s}$ and its amplitude was $+/-0.6^{\circ} \mathrm{C} . \mathrm{T}_{\mathrm{g}}, \mathrm{T}_{\mathrm{m}}$ and $T_{c}$ were taken as the inflection points of the increment of specific heat at respectively the glass-rubber transition and the onset of the melting or crystallization peak.

Thermogravimetric measurements (TGA) were carried out using a Netzsch STA409 thermal analyzer. Around $50 \mathrm{mg}$ of the sample was heated from room temperature up to $400^{\circ} \mathrm{C}$ at $10^{\circ} \mathrm{C} \cdot \mathrm{min}^{-1}$ in an air flow. The degradation temperature, $\mathrm{T}_{\mathrm{d}}$, corresponds to a $5 \%$ weight loss.

\section{$\underline{\text { Rheometry }}$}

Rheometrical measurements were performed using a TA ARG2 rotational rheometer. Viscosity was determined through controlled shear measurements using both parallel plates and cone and plate geometry. Viscosity measurement under shearing involves imposing a 
shear rate $\dot{\gamma}\left(\mathrm{s}^{-1}\right)$ on the sample, and measuring the resulting shear stress $\tau(\mathrm{Pa})$. The viscosity $\eta$ (Pa.s) can be calculated by dividing the shear stress by the shear rate.

$$
\eta=\frac{\tau}{\dot{\gamma}}
$$

Depending on the temperature, different geometries have to be used. In the first case, the ionic liquids were characterized in a temperature range between ambient and $60^{\circ} \mathrm{C}$, controlled through a Peltier effect heating plate. The diameter of the plate was such that a $60 \mathrm{~mm}$ cone with $1^{\circ}$ truncature could be used, thus allowing accurate measurements to be performed. For temperatures above $60^{\circ} \mathrm{C}$, an oven was used with the rheometer. Due to the oven inner diameter, these measurements were associated with $25 \mathrm{~mm}$-diameter parallel plate geometry, with a 1 mm gap between the two plates.

As the ionic liquids tested have low viscosities, the rheological tests were based on continuous flow measurements, conducted in a dry nitrogen atmosphere. Due to the high hydrophilic nature of the PCILs, a dry atmosphere must be used to avoid water pollution, which would strongly impact on viscosity.

\section{NMR experiments}

NMR experiments on the pure PCILs, i.e. free of any added solvent, were carried out on a Bruker Avance NMR 400 spectrometer equipped with a broadband probe with $z$-axis gradient for the measurement of ${ }^{1} \mathrm{H}$ and ${ }^{19} \mathrm{~F}$ spectra and the determination of ${ }^{1} \mathrm{H}$ and ${ }^{19} \mathrm{~F}$ diffusion coefficients. Temperatures were controlled within the $300-420 \mathrm{~K}$ range with a Bruker BVT3000 system ( $\pm 1 \mathrm{~K}$ regulation). The temperature was calibrated before each set of measurements by using the standard procedure with a reference ethylene glycol sample. PCILs were introduced in $4 \mathrm{~mm}$-diameter NMR tubes and sealed in a glove box under argon 
in order to avoid any contact with moisture. Narrow tubes were chosen in order to avoid convection movements within these low viscosity liquids.

Self-diffusion coefficients were determined with the pulsed field gradient stimulated echo and LED sequence using 2 spoil gradients. Self-diffusion coefficients were determined from the classical relationship $\ln \left(I / I_{0}\right)=-\gamma^{2} D g^{2} \delta^{2}(\Delta-\delta / 3)$ (21) where $\mathrm{g}$ is the magnitude of the two gradient pulses, $\Delta$ is the time interval between these pulses, $\delta$ is their duration, $\gamma$ is the gyromagnetic ratio of the nucleus under study and $\mathrm{I}$ and $\mathrm{I}_{0}$ are the areas of the signals obtained respectively with and without gradient pulses. The magnitude of the pulsed field gradient was varied between 0 and $45 \mathrm{G} . \mathrm{cm}^{-1}$; the diffusion time $\Delta$ between two pulses was fixed at $200 \mathrm{~ms}$, and the pulse duration $\delta$ was set between 3 and $20 \mathrm{~ms}$, depending on the diffusion coefficient of mobile species. $\pi / 2$ pulse widths were calibrated to $8.5 \mu$ s and $17.5 \mu$ s for ${ }^{1} \mathrm{H}$ and ${ }^{19} \mathrm{~F}$ respectively .

Membrane elaboration

Membranes based on Nafion

First the Nafion ${ }^{\circledR} 117$ membrane was immersed in a $2 \mathrm{M} \mathrm{HNO}_{3}$ aqueous solution and heated at water reflux temperature for $2 \mathrm{~h}$ in order to recover all the Nafion acidic functions $\left(\mathrm{Naf}-\mathrm{H}^{+}\right)$. Then, the acidified Nafion membrane, washed several times with deionisated water, was neutralized by the amine constitutive of the PCIL's further used. Neutralization was performed by immersing the membranes at room temperature for $24 \mathrm{~h}$ in a 50/50 v/v mixture of ethanol and $4 \mathrm{M}$ aqueous solution of amine. The membranes were then washed with pure water and dried for $48 \mathrm{~h}$ under vacuum at $130^{\circ} \mathrm{C}$. Then the neutralized membranes were transferred to a glove box. The dried neutralized membranes were immersed in the corresponding PCIL heated to $80^{\circ} \mathrm{C}$ and PCIL uptake was measured at different times. The PCIL swollen membranes were removed from the PCIL and kept in the glove box at room temperature for at least a week. The 
weight of the membranes was checked every $24 \mathrm{~h}$ over a week in order to evaluate membrane stability, and more specifically PCIL release from the membrane.

\section{Membranes based on sulfonated polysulfone}

Sulfonated Polyether sulfone was neutralized by the same amine than that used to synthesize the PCILs. The synthesis and the characterisation of sulfonated polysulfone were previously described $[23,24]$. Then a mixture of the latter with the selected amount of PCIL was dissolved in a common solvent i.e. Diethylene glycol monoethyl ether (DGME). After casting the solution, DGME was evaporated leading to the membrane.

\section{Conductivity measurements}

Conductivities were determined by electrochemical impedance spectroscopy using an HP 4192A Impedance Analyser in the frequency range $5 \mathrm{~Hz}-13 \mathrm{MHz}$.

A conductivity cell consisting of platinum electrodes was filled by the PCIL and closed in a glove box. The cell constant of c.a. $1 \mathrm{~cm}^{-1}$ was determined using a standard $\mathrm{KCl}$ aqueous solution. The measurements were carried out from $20^{\circ} \mathrm{C}$ up to a maximum temperature of $150^{\circ} \mathrm{C}$, the temperature being equilibrated for $2 \mathrm{~h}$ before each measurement.

The membranes were placed between two stainless steel electrodes under argon (in glove box) in a Swagelok cell with Teflon joints and spacers, and measurements were performed from $20^{\circ} \mathrm{C}$ to $150^{\circ} \mathrm{C}$. The temperature was equilibrated for $2 \mathrm{~h}$ before each measurement.

Membrane thickness was determined with a Digimatic MDG-25SB micrometer by placing the membrane between two discs.

The spectra were recorded between $13 \mathrm{MHz}$ and $5 \mathrm{~Hz}$. Due to the high conductivity of PCIL and their membrane, at high frequency the resistive contribution of the set-up to the overall resistance (leads and connections) may range from 1 to $10 \%$ of the high frequency response of the membrane. For this reason, the impedances measured are corrected from the set-up impedance measured in the same frequency range. This impedance can be represented, below 
$4 \mathrm{MHz}$, using an equivalent circuit consisting of an inductance of $5 \mu \mathrm{H}$ associated with a resistance of $1.3 \Omega$ in series. The resistance of the membrane is taken at the high frequency intercept with the real axis in the Nyquist plot, which is usually between $10^{6}$ and $10^{4} \mathrm{~Hz}$.

Dynamic mechanical analysis

Dynamic mechanical analysis (DMA) measurements were carried out with a TA Instruments DMA Q800 spectrometer working in the tensile mode. The strain magnitude was fixed at $0.01 \%$. This value ensured that the tests were made in the linear viscoelastic domain. Measurements were performed in isochronal conditions $(1 \mathrm{~Hz})$ and the temperature was varied between -100 and $150^{\circ} \mathrm{C}$ at $2^{\circ} \mathrm{C} / \mathrm{min}$.

\section{Results and discussion}

The more convenient chemical route to obtain PCILs involves the neutralisation of a Brønsted acid by a Lewis base such as aliphatic acyclic or cyclic amine, or an aromatic amine. Both amine and acid structures modulate PCIL properties. It is hoped that this paper will contribute to a general discussion of the influence of amine structures on PCIL physicochemical properties and, more specifically, on conduction mechanisms in PCILs. For this purpose, we decided to use one single Brønsted acid, namely trifluoromethanesulfonic, and to neutralize it with different amines such as primary amines, secondary and tertiary aliphatic acyclic and cyclic amines. Secondary amines incorporating electron donor atoms such as oxygen, i.e. ether substituent, or nitrogen, i.e. diamine, were also used. In the latter, only one amine function was neutralized (Table 1). In addition, with a view to clarifying the impact of water on PCIL properties and conduction mechanisms, controlled amounts of water were added. The resulting humidified PCILs were then characterised and discussed. In addition to the study of PCIL- water blends, the PCIL blends with several host polymers were investigated. 


\subsection{Anhydrous PCIL physico-chemical properties}

\section{$\underline{\text { 3.1.1. Thermal behaviour }}$}

The thermal behaviour of PCILs is relevant to their physicochemical properties. Low glass transition and melting temperatures in combination with high thermal stability are the general requirements for good ionic liquids.

As previously observed by Nakamoto et al [11], the melting temperature of aliphatic primary amines and aliphatic acyclic symmetrical secondary/tertiary amines (1-12) increases with the number of carbons. For PCILs based on cyclic aliphatic ammoniums (17-23), the melting temperatures $(\mathrm{Tm})$ are higher than those of their acyclic aliphatic ammonium homologues (for example $17 v_{s}$ 4). Furthermore, the Tm of five-membered heterocycles e.g. 17 is higher than that of the six-membered heterocycle e.g. 20. This behavior can be ascribed to heterocycle geometry and flexibility.

For PCILs resulting from acyclic secondary amines, a much lower Tm was observed in the case of 13 (BMEA-TF). This might be explained (1) by the flexibility induced by the ether function, and (2) by the interaction between the oxygen lone pair and the ammonium. Indeed, the latter decreases the positive charge on nitrogen and, therefore, decreases ion-ion interactions [17]. Furthermore, the inter- and/or intra-molecular interactions between the ether function and the positive charge might generate a higher local disorder.

Another approach to decrease $\mathrm{Tm}$ [11] consists in preparing PCILs from dissymmetrical amines (14-16). In PCILs based on acyclic symmetrical tertiary ammoniums, the increase in ammonium substituent length leads, except for TEA-TF (6), to a Tm increase. Surprisingly, 6 exhibits the lowest Tm of overall PCILs based on aliphatic acyclic ammonium. For the tertiary cyclic ammonium, the increase in asymmetry, resulting from the exocyclic substituent and its length, induces a sharp decrease of Tm that drops to $6^{\circ} \mathrm{C}$ for BuPyrA-TF. As observed 
for BMEA-TF, the presence of an ether function in a five-membered cycle i.e. morpholinium (23) decreases $T_{m}(\mathbf{2 3} v s \mathbf{2 2})$. In this heterocyclic ammonium, the $T_{m}$ decrease cannot be ascribed to a possible flexibility induced by the ether function, and the decisive factor should be the interaction between the lone pair and the ammonium.

While the ether oxygen lone pair cannot result in stable oxoniums, by reacting with $\mathrm{H}^{+}$, the situation is completely modified when the lone pair is carried by a much stronger Brønsted base e.g. amine as in diamines.

Thus promising PCILs were obtained by neutralization of triflic acid (TF) with different diamines, $\mathrm{H}_{2} \mathrm{~N}-\mathrm{R}-\mathrm{NH}_{2}(\mathrm{R}=$ alkyl). The neutralization of both amino groups leads to very high Tms, which are unsuitable in PEMFC, while the diamine half-neutralization seems very attractive. Tm is not only much lower than that for diammonium but also than those of most of the monoammonium-based PCILs. ${ }^{1} \mathrm{H}$ NMR spectra did not allow the presence of free amine to be observed, reflecting the fact that the proton interacts with both amino groups of the diamine. This interaction, which delocalises the positive charge between two nitrogen atoms, might be intra and/or inter-molecular (figure 1). By generating disorder, these interactions decrease $\mathrm{Tm}$. At this stage, it is frustrating to realise that we are unable to discriminate between intra and intermolecular chelation of the proton. This probably depends on the length of $\mathrm{R}$ and we therefore intend to perform comparative ab initio calculations to determine the more plausible interactions, depending on $\mathrm{R}$ length.

Figure 1.

With regard to the $\mathrm{Tg}$ values of these PCILs, the high melting points obtained for symmetrical salts (1-12) indicate their capacity to crystallize. As previously observed by Watanabe [11] and Angell [14] (for series of primary, secondary and ternary ammonium salts), the excessive crystalline character of symmetrical salts prevents an accurate 
determination of Tgs, even after melting and soaking PCILs in liquid nitrogen. Thus Tgs were only determined for a few of our PCILs.

As for thermal stability characterized by TGA experiments, it has been shown that not all monoammonium-based PCILs undergo weight loss up to at least $300^{\circ} \mathrm{C}$. On the contrary, diamine-based PCILs undergo weight loss from lower temperatures. Indeed such weight loss occurs in two stages i.e. 240 and $500^{\circ} \mathrm{C}$ for 25 . At $240^{\circ} \mathrm{C}$, the weight loss is around $13 \%$. It might correspond to a thermally activated disproportionation of PCIL into diammonium and starting diamine. The latter can obviously evaporate but it must be emphasized that the weight loss occurs at a temperature exceeding, from about $100^{\circ} \mathrm{C}$, the boiling point of the diamine. Taking into account this thermal event, there may be a risk that the preliminary purification of diamine-based PCIL, involving its thermal drying (at $100^{\circ} \mathrm{C}$ under vacuum), will lead to its partial disproportionation resulting in diamine evaporation. Nevertheless, neither ${ }^{1} \mathrm{H}$ NMR nor elemental analyses revealed any removal of diamine relating to the purification process.

Table 1

\subsubsection{Viscosity and conductivity}

PCIL conductivity depends on both ion concentration and viscosity. Indeed, high volumic concentration in PCIL favors conductivity but, at the same time, leads to high density. The densities of triflate-based PCILs range between 1.2 and 1.7 and are close to the reported data [24]. Density variation is related to both steric hindrance around the ammonium and ion concentration. The more hindered the ammonium, the lower its density. This is reflected in the lengthening of the alkyl substituent of the ammonium salt. In order to calculate the density at $130^{\circ} \mathrm{C}$, a linear expression proposed in the literature $[19,21]$ was used.

As conductivity depends on ionic mobility, which in turn is dependent on viscosity, a rheological analysis is indispensable in order to assess the influence of viscosity on 
conductivity. Viscosity is dependent on ion-ion interactions, Van der Waals interactions and hydrogen bonding (increased interaction leading to higher viscosities), but also on molecular weight. Some of the PCILs, although well-adapted to membranes operating at $130^{\circ} \mathrm{C}$, have unfortunately high melting points making viscosity measurements impossible. The viscosity data of the others are compatible with findings in the literature [27]. For PCILs originating both from dissymmetrical amines and diamines, viscosities increase with alkyl chain lengths. The viscosities of PCIL decrease with the starting amine according to dissymmetrical monoamines $<$ symmetrical monoamines < diamines. The high viscosities of PCILs, originating from half-neutralized diamines, are mainly related to intermolecular interactions but also, to a lesser extent, to their assumed higher dissociation degree. The latter, due to the high donor number of the un-neutralized amino group and to its polarity, should indeed be higher for this PCIL series. For 13 (BMA-TF), taking into account the presence of oxygen, viscosity increases with regard to the other PCILs based on monoammoniums can be expected. This gain in viscosity, due to intermolecular interactions for 13 (BMA-TF), should partly counterbalance the decrease in viscosity related to the high flexibility induced by the ether function.

The maximum conductivity gap, at $130^{\circ} \mathrm{C}$, between PCILs obtained from symmetrical or dissymmetrical amines, is limited and reaches only a factor of 1.5 (Table 1, Figure 2 a). As expected the conductivity dependence on temperature of monoammonium based PCILs exhibits VTF type behaviour with pseudo-energy activation ranging between 2 and 5 KJ.mol' 1.

Due to the high viscosities, fairly low conductivities were expected for PCILs obtained from half-neutralized diamines. Surprisingly, 24-25 exhibit conductivities close to those of the less viscous monoammonium-based PCILs. Contrary to monoammoniums, conductivity dependence on temperature of half-neutralized diamine-based PCILs (Figure 2b) is not a very 
good match with classical VTF behaviour. From these results, it might be inferred that, in half-neutralized diamine-based PCILs, conduction is not exclusively vehicular as in monoammonium-based PCILs..

Figure 2.

\subsubsection{Self-Diffusion Coefficient}

PFG-NMR was used to investigate the structure of these liquids by measuring a dynamic property (on a macroscopic space scale of 1-100 $\mu \mathrm{m}$ ). Thus, the self-diffusion coefficients of $\mathrm{H}^{+}\left(\mathrm{D}_{\mathrm{H}+}\right)$, amine $\left(\mathrm{D}_{\mathrm{am}}\right)$, ammonium $\left(\mathrm{D}_{\mathrm{am}}\right)$ and the anion $\left(\mathrm{D}_{\text {anion }}\right)$ were measured in these different systems by PFG-NMR. Their temperature-dependence, between PCIL Tm and 420 $\mathrm{K}$, is compared in figure 3 . Table 2 gathers, at $400 \mathrm{~K}$, the diffusion coefficients of several PCILs.

Table 2.

Figure 3.

From Table 2 and Figure 3, two observations may be made about the $\mathrm{H}^{+}$diffusion mechanism. Firstly, with regard to PCILs based on monoammoniums, in which the diffusion coefficients of $\mathrm{H}^{+}$and the amine cannot be discriminated, it can be seen that cationic conduction is exclusively ensured by the ammonium. When ammonium bulkiness increases, the difference between $D_{\text {amine }}$ and $D_{\text {anion }}$ becomes very slight, in agreement with the size effect on the diffusion described by Watanabe [10].

Secondly, unlike the previous PCILs, those resulting from a half-neutralization of diamines, 24-26 exhibit two distinct diffusion coefficients i.e. $\mathrm{H}^{+}$and diamine. This means that, in addition to the previous vehicular mechanism, another conduction mechanism, i.e. a Grotthuss-like mechanism, takes place as in imidazole/ HTFSI PCIL [28]. The existence of both conduction mechanisms helps explain why high conductivities can be obtained for this 
kind of PCIL while the viscosities are much higher than those of PCILs originating from monoamines. At this stage it is difficult to ascribe to each conduction mechanism a quantitative contribution, but there is every indication that the Grotthuss-like mechanism predominates at low temperatures and that its impact decreases at high temperatures. Indeed at high temperatures, PCIL viscosity strongly decreases, favouring the vehicular mechanism. If ionic liquids are totally dissociated (free ions), the molar conductivity of the PCILs can be assessed from the self-diffusion coefficients, $\Lambda_{\mathrm{NMR}}$, using the Nernst-Einstein equation,

$$
\Lambda_{N M R}=\frac{N_{A} e^{2}\left(D_{\text {cation }}+D_{\text {anion }}\right)}{k T}=\frac{F^{2}\left(D_{\text {cation }}+D_{\text {anion }}\right)}{k T}
$$

where $D_{\text {cation }}$ and $D_{\text {anion }}$ are the diffusion coefficients of the proton and anion (as determined by PFG-NMR), $N_{A}$ is the Avogadro number, $e$ is the electric charge on each ionic carrier, and $k$ is the Boltzmann constant. However, the diffusion coefficients determined by NMR relate to all the species present in the liquid, namely free ions, ion pairs, and also larger aggregates. On the other hand, the experimental conductivities only depend on the mobility of the charged species. Thus, the Nernst-Einstein equation can be used to assess the degree of dissociation. Indeed, due to ionic association, the molar conductivity calculated from NMR is overestimated with respect to the experimental one $\left(\Lambda_{\text {imp }}\right)$. The dissociation degrees were determined at $130^{\circ} \mathrm{C}$ for several PCILs. Most of the dissociation degrees of monoammoniumbased PCILs are around 30\%. The higher dissociation degree of 13 (BMEA-TF), around 40\%, should be emphasized. In such an ammonium, the inter and/or intramolecular interactions between the oxygen lone pair and the ammonium acts to partly delocalize the positive charge and therefore increase the dissociation. In PCILs based on half-neutralized diamines, the delocalizing effect is probably much stronger but cannot be assessed given that the respective contributions of vehicular vs Grotthuss mechanisms are not quantified. The results obtained are presented in Table 2.

Cationic transference numbers: 
From the diffusion coefficients, the cationic transference numbers were calculated from eq.6.

$$
t^{+}=\frac{D_{H+}}{D_{H+}+D_{\text {anion }}}
$$

The cationic transference numbers of monoammonium based PCILs are close to 0.5 , with the highest, 0.56 , being obtained for PCIL 6 in accordance with the relatively small size of the ammonium. When ammonium size increases, $\mathrm{T}^{+}$tends to be equal to 0.5 . For these PCILs $\mathrm{T}^{+}$ is almost constant $v s$ temperature. For the PCILs based on half-neutralized diamines, $\mathrm{T}^{+}$is appreciably higher than 0.5 and decreases when the temperature increases. These higher $\mathrm{T}^{+}$ and the fact they decrease with higher temperatures (Figure 4) are probably respectively related to the Grotthuss mechanism and the increase in vehicular contribution with temperature.

Figure 4.

\subsubsection{Electrochemical stability}

The electrochemical stability of PCILs was mainly characterized by cyclic voltammetry $(\mathrm{CV})$, performed in acetonitrile $+0.1 \mathrm{M}$ TBAP as electrolyte (see experimental section). Their electrochemical behaviour was compared to that of the starting amine.

\section{PCILs from monoamine}

Concerning the starting amine, it is well known that amine can be oxidized through an irreversible electron oxidation process leading to an intermediate radical cation according to next equation [29].

$\mathrm{R}_{1} \mathrm{R}_{2} \mathrm{R}_{3} \mathrm{~N} \rightarrow \mathrm{R}_{1} \mathrm{R}_{2} \mathrm{R}_{3} \mathrm{~N}^{+\cdot}+\mathrm{e}^{-}$

For all the amines used, the CVs exhibit one anodic peak at Epa whose value essentially depends on the amine structure i.e. the number and structure of nitrogen substituents. Thus figure 5 shows that the Epa value is lowest for a tertiary amine (TPrA) at 1.09, higher for a 
secondary amine (DPrA) at 1.35 , and highest for a primary amine $(\operatorname{PrA})$ at 1.92 . It must be emphasized that the order of Epa values is in fairly good agreement with the order of the inductive electron-donating effect exerted by the alkyl substituents of the nitrogen atom.

Figure 5:

In the case of PCILs, protonation of the monoamines leads to the disappearance of the oxidation peak of the free amines attesting to their purity, whereas no other oxidation process is detectable up to $2.5 \mathrm{~V} / \mathrm{SHE}$ (Figure 6).

Figure 6

In the cathodic region, the quasi reversible reduction of the ammonium salt is observed. This process corresponds overall to the reduction of the proton, generating $\mathrm{H}_{2}$.

$2 \mathrm{R}_{1} \mathrm{R}_{2} \mathrm{R}_{3} \mathrm{NH}^{+}+2 \mathrm{e}^{-} \rightarrow \quad 2 \mathrm{R}_{1} \mathrm{R}_{2} \mathrm{R}_{3} \mathrm{~N}+\mathrm{H}_{2}$

$E_{1 / 2}$ values connected with the basicity of the starting amines were expected. However, due to adsorption phenomena on the platinum electrode $[29,30]$ coupled to the electron transfer, distortions of the CVs were observed, making it fairly difficult to accurately determine $\mathrm{E}_{1 / 2}$. This is illustrated by the CV comparison of PCILs 7, 12 and $\mathbf{9}$ whose $E_{1 / 2}$ values are close $(0.67,0.69,0.65$ respectively). Nevertheless, from 7 (PrA-TF) up to 9 (TrPA-TF) the electron-donating effect increases with the number of alkyl substituents and should make the reduction process more difficult. This adsorption process is particularly evidenced by the high $\Delta$ Ep value for 7, 14-16, which is higher than $300 \mathrm{mV}$.

\section{PCILs from diamines}

Two successive nitrogen oxidation processes were expected in diamines. In fact, the CVs show a single broad irreversible anodic peak at Epa around 1.5V/SHE. It may be suggested 
that the wide breadth of this signal indicates that the two one-electron nitrogen-centred transfers are superimposed.

The PCILs based on half-neutralized diamines have both a free amino group and a protonated one. Thus, their CVs show one irreversible anodic and one quasi reversible cathodic process. The oxidation peak remains very broad, whereas the half-protonation shifts the Epa towards to a more positive value at around 1.9V/SHE (Figure 7).

\section{Figure 7}

This result seems to prove that when one amino group is neutralized, the proton is not exclusively located on one amino group of the PCILs and that it interacts with both, through a fast protonic equilibrium. Depending on the structure of the PCILs, this interaction may be either intramolecular for short $\mathrm{N}$ to $\mathrm{N}$ distance (DAEt-TF, 24) or intermolecular when the alkyl chain separating the amino groups increases (DADc-TF, 26). It should be noted that this protonic exchange has been clearly observed by ${ }^{1} \mathrm{H}$ and ${ }^{15} \mathrm{~N}$ NMR analyses, as previously described, since labile protons (i.e. of $\mathrm{NH}_{2}$ and $\mathrm{NH}_{3}{ }^{+}$moieties) appear as a single well-defined signal.

In the cathodic region, these PCILs behave similarly to monoammonium-based PCILs. Here again, the $E_{1 / 2}$ value and the shape of the CVs strongly depend on the nature of the PCIL (Figure 6). Here, it can be assumed that the adsorption process coupled to the electron transfer is more intense than that observed for monoammoniums since $\Delta \mathrm{Ep}$ values higher than 500 $\mathrm{mV}$ are observed.

\subsection{PCIL blends}

\subsubsection{Humidified PCILs}


Prior to any characterization, PCILs were thoroughly dried, given that the presence of water, even at very low concentrations, is expected to have an impact on PCIL properties e.g. conductivity. In order to quantify this impact we investigated the blends of (TEA-TF, 6) and water. To express the water content, we will use the ratio (in moles) $\mathrm{x} / \mathrm{y}$, where $\mathrm{x}$ is the number of moles of water and y the number of moles of PCIL. In table 3 are gathered the viscosities, conductivities and diffusion coefficients at 40 and $80^{\circ} \mathrm{C}$ of these blends. It can be emphasized that water has a distinct impact on the PCIL characteristics. Following water uptake, conductivity increases due to water's outstanding properties, namely 1) its very low viscosity that decreases the viscosity of the blend PCIL/water, 2) its high dielectric constant that favours ion-pair dissociation, 3) its highly solvating ability reflected by its Donor Number DN, close to that of tetrahydrofurane, and its high Acceptor Number AN, 4) its molecules that can significantly contribute to proton mobility.

Table 3 .

In fully dried TEA-TF PCIL, the proton and amine have close diffusion coefficient values. At low water concentration, $1 / 10$, and at temperatures below $80^{\circ} \mathrm{C}$, the diffusion coefficients (amine, anion and proton) slightly increase in relation to those of the dry sample, and seem to be proportional to the decrease in viscosity. Moreover, the water diffusion coefficient $\left(\mathrm{D}_{\mathrm{H} 2 \mathrm{O}}\right)$ is much higher than those of the PCIL components. This is related to the very low molecular weight of water with regard to the ammonium and triflate anion. For this blend, and up to $80^{\circ} \mathrm{C}$, a vehicular mechanism involving ammonium, as in dried PCIL, can be assumed. On the other hand, above $80^{\circ} \mathrm{C}$, a new proton diffusion coefficient appears whose value is intermediate between that of the water and that of the amine. It may therefore be assumed that from $80^{\circ} \mathrm{C}$ a rapid proton exchange takes place between the amine and water and that the proton migrates via both a Grotthuss mechanism (the proton jumping between water-amine, water-water or amine-amine) and a vehicular mechanism involving ammonium and oxonium. 


\section{PCILs hosted by neutral polymers}

PVDF-based copolymers, namely polyvinylidene fluoride-co-polyhexafluoropropene PVDF-HFP, have been observed to be good host polymers for PCILs [31]. However, the authors observed a confinement of PCILs, high conductivities only being obtained at high PCIL uptake. However, this makes the thermomechanical performances of these membranes at high temperatures questionable. We attempted unsuccessfully to blend PCILs with highperformance non-ionic polymers such as polyethersulfone (UDEL or RADEL ${ }^{\circledR}$ grades) or polyether-ether ketone PEEK. The poor affinity of these polymers for the ionic liquids resulted in insignificant PCIL uptakes.

\section{PCILs hosted by ionomers}


We observed fairly good combinations of mechanical and conductive performances for blends of Nafion $117 \AA[19,20,21]$ with PCILs. In order to avoid the release of molecular acids resulting from $\mathrm{H}^{+}$/ammonium exchange, Nafion 117 was first neutralized with the same amine as used to prepare the PCIL. The storage modulus, E' above $120^{\circ} \mathrm{C}$, was, however, in the range of 1 to $3 \mathrm{MPa}$. Mixing neutralized Nafion 117 with the PCILs based on monoammonium cation, reported in this paper, results unfortunately in the same behaviour, regarding conductivity and E', as observed in our previous reports [19, 20, 21]. Although these E' values seem too low to allow using Nafion as a host polymer for high-temperature PEMFC membranes, they are high enough to allow using PCIL hosted by Nafion in the electrode active layers.

When Nafion 117 is neutralized by diamines, a neat increase of E' is observed, as shown in Figure 8. This compares the thermal evolution of E' for Nafion neutralized by either a monoamine or several diamines $\mathrm{H}_{2} \mathrm{~N}-\left(\mathrm{CH}_{2}\right)_{\mathrm{n}}-\mathrm{NH}_{2}$. These high E' values, which originate from the physical cross-linking of Nafion, are much higher than those of monoammoniumbased Nafion. Thus, at $130^{\circ} \mathrm{C}$, E' reaches $434 \mathrm{MPa}$ for $\mathrm{n}=2$ and progressively decreases down to $151 \mathrm{MPa}$ for $\mathrm{n}=6$. Following PCIL uptake, a sharp E' decrease is observed. E' close to $110 \mathrm{MPa}$ was measured for $\mathrm{n}=2$ while, for $\mathrm{n}>2$, E' drops to $10-17 \mathrm{MPa}$. Conductivity is strongly decreased by the Nafion cross-linking and ranges between 2 and $5 \mathrm{mS} / \mathrm{cm}$ at $130^{\circ} \mathrm{C}$ for PCIL uptake of $40 \%$. However, membrane reinforcement, allowing the membrane to be shaped in thinner films, will counterbalance the effect of the conductivity drop on internal resistance.

Figure 8 .

Other ionomers based on High Performance polymeric backbones were also evaluated. Thus, a sulfonated polysulfone ionomer, having an Ionic Exchange Capacity of $1.3 \mathrm{meq} / \mathrm{g}$, was blended by PCILs. High PCIL uptakes were observed with various PCILs, which was 


\section{General discussion: Future prospects for PCIL-based membranes}

In today's PEMFCs that operate below $80^{\circ} \mathrm{C}$, the membrane consists of an ionomer. The ionic moieties cannot therefore be eluted by the water flux that comes from both the electrochemical reaction and the gas humidifiers. However, in a PEMFC with $\mathrm{H}_{3} \mathrm{PO}_{4}$ and PCIL-based membranes, the proton-conducting moiety would be removed when the PEMFC operates below $100^{\circ} \mathrm{C}$. On the other hand, above $120^{\circ} \mathrm{C}$, the PEMFC produces water at the vapour state, so that the release of molecular proton-conductors as $\mathrm{H}_{3} \mathrm{PO}_{4}$ and PCIL need not be a concern. The ideal solution, even though it seems illusory, should consist in keeping high conductivities while using fully hydrophobic PCILs to operate PEMFCs from $-20^{\circ}$ up to temperatures higher than $120^{\circ} \mathrm{C}$. A pragmatic solution for $\mathrm{EV}$ implementation should therefore consist in hybridizing PEMFCs with batteries in order to maintain PEMFCs at $120^{\circ} \mathrm{C}$. This implies that PEMFCs have to be started and stopped at $120^{\circ} \mathrm{C}$.

Although membranes with a good combination of mechanical properties and conductivities have recently been obtained (patent pending), several issues still remain. The first concerns the degree of purity of PCILs produced on an industrial scale. Indeed PCILs, liquids at sub-ambient temperature, can be neither distilled nor crystallized. In the case of an operation above $120^{\circ} \mathrm{C}$, however, this problem can be solved by selecting PCILs from among 
those whose melting point is around $30-40^{\circ} \mathrm{C}$. As a matter of fact, they could easily be purified by recrystallization.

Another issue relates to the production on the cathode of amine that may be removed by evaporation. To prevent this elimination, an excess of non-volatile acid might be used, provided this molecular acid damages neither the membrane nor the electrodes and is perfectly miscible with the PCIL. The use of half-neutralized diamines appears an attractive solution, as it will limit, but not eliminate, the risk of removal related to a disproportionation of the monoammonium into a mixture of diamine and diammonium. Special attention must therefore be paid to the boiling point of the diamine, which should be as high as possible. Lastly an adsorption on the electrocatalyst of the amines, which might be assimilated to poisoning, may be a problem. Decreasing the amine basicity and increasing the steric hindrance around the nitrogen should be envisaged in view to avoid, or at least drastically limit, this adsorption.

Despite these issues, PCIL-based membranes have indisputable assets and remain among the most plausible candidates for High Temperature PEMFCs. In addition to their high conductivity at the anhydrous state, which will be appreciably enhanced by the unavoidable trapping of part of the water produced by the PEMFC, these hydrophilic PCILs should prevent, or at least limit, the degradation of the mechanical performance of the fairly hydrophobic polymeric backbone. Indeed, most of the oxidative by-products of the PEMFC are hydrophilic and should, if possible, remain in the PCILs. It might be assumed that, owing to the high content of PCILs, the impact of their possible (but limited) degradation on the membrane lifespan should be markedly lower than in classical membranes.

To conclude, research in this new scientific field should focus on highly stable (chemical, electrochemical, thermal) PCILs, which are easy to purify into an electrochemical grade and should provide, once blended to functional polymers, an optimal combination of 


\section{Conclusion}

This contribution that gathers the physico-chemical characterizations of a wide variety of ammoniums based Proton-Conducting Ionic Liquids allows emphasizing the high complexity of these molecular salts. While the general trend is the preparation of PCILs exhibiting high conductivities in a wide temperature range, we voluntarily selected crystalline salts. As a matter of fact (i) the targeted application deals with PCIL based membranes operating only at temperatures higher than $100^{\circ} \mathrm{C}$, in order to avoid any PCIL removal by liquid water produced by the PEMFC and (ii) their crystalline nature allows expecting an easy scale-up of the PCIL purification by recrystallization. Although the amount of water trapped by a PEMFC membrane operating at $\mathrm{T}>120^{\circ} \mathrm{C}$ cannot be assessed, part of the water produced by the PEMFC will presumably impregnate the membrane. The investigation of the water influence on the PCILs properties shows that viscosity sharply decreases in presence of water, while conductivity and diffusion coefficients significantly increase. In addition, water intrinsically contributes to the conductivity enhancement, through a Grotthuss-like mechanism that has been unambiguously evidenced. Therefore, the unavoidable humidification of the membrane, during the PEMFC operation, will level out the PCILs performances.

The more promising results deal with half-neutralized diamine based PCILs, whose conduction proceeds by both vehicular and Grotthuss-like mechanisms. In addition, despite their high viscosity, these PCILs exhibit high conductivity and cationic transference number 
at $130^{\circ} \mathrm{C}$. Lastly, they were found to reinforce markedly, through physical cross-linking, the Nafion based membranes.

Acknowledgements: the authors express their gratitude to ANR PAN-H and ERAS-Labo that respectively granted the national project CLIPPAC and the PhD thesis of Mathieu Martinez.

\section{References}

1. P. Genova-Dimitrova, B. Baradie, D. Foscallo, C. Poinsignon, J-Y. Sanchez, J. Membr. Sci., 2001, 185, 59.

2. G. Alberti, M. Casciola, Annu. Rev. Mater. Res., 2003, 33, 129.

3. P. Donoso, W. Gorecki, C. Berthier, F. Defendini, C. Poinsignon, M.B. Armand, Solid State Ionics, 1988, 28-30, 969.

4. H. Schmidt, M.Popall, F.Rousseau, C.Poinsignon, M.Armand, J-Y.Sanchez, $2^{\text {nd }}$ Int. Symposium on polymer electrolytes, Ed. B. Scrosati, Elsevier Sciences Publishers, 1990, p.35

5. J. J. Fontanella, M.C. Wintersgill, J.S. Wainright, R.F. Savinell,M. Litt, Electrochim. Acta 1998, 43, 1289.

6. Q. Li, R. He, J. Jensen, N.J. Bjerrum, Fuel Cells, 2004, 4, 147-159.

7. D. Bruijn, A. Frank, R.C. Makkus, R.K.A.M. Mallant, G.J.M. Janssen, Advances in Fuel Cells, 2007, 1, 235.

8. Md A B H Susan, A. Noda S. Mitsushima, M. Watanabe, Chem. Comm. 2003, 8, 938939.

9. Md. A B H Susan, A. Noda, M. Watanabe M, Proceedings - Electrochem. Soc., 2006, 2004-2024. 
10. H. Nakamoto, A. Noda, K. Hayamizu, S. Hayashi, H. Hamaguchi, M. Watanabe, J. Phys. Chem. C, 2007, 111, 1541.

11. H. Nakamoto, M. Watanabe, Chem. Comm., 2007, 2539.

12. M. Watanabe, Materials Integration, 2003, 16, 33.

13. CA. Angell, N. Byrne, J-P. Belieres, Acc. Chem. Res., 2007, 40, 1228.

14. J.P. Belieres, C.A. Angell, J. Phys. Chem. B, 2007, 111(18), 4926.

15. M. Yoshizawa, W. Xu, C.A. Angell, J. Am. Chem. Soc., 2003, 125, 15411.

16. TL Greaves, C.JD. Drummond, Protic Ionic Liquids: Properties and Applications., Chem. Rev., 2008, 108, 206.

17. C. Iojoiu, P. Judeinstein, J-Y. Sanchez, Electrochim. Acta, 2007, 53, 1395.

18. P. Judeinstein, C. Iojoiu, J-Y. Sanchez,B. Ancian, J. Phys. Chem. B, 2008, 112, 3680.

19. C. Iojoiu, M. Martinez, M. Hanna, Y. Molmeret, L. Cointeaux, J.-C. Leprêtre, N. El Kissi, J. Guindet, P. Judeinstein, J.-Y. Sanchez, Polym. for Adv. Techn., 2008, 19, 1406.

20. V. di Noto, E. Negro, J-Y Sanchez, C. Iojoiu, J. Am. Chem. Soc., 2010, 132(7), 2183.

21. M. Martinez, C. Iojoiu, P. Judeinstein, J-C Lepretre, L; Cointeaux, J-Y. Sanchez, J. Power Sources, in press.

22. V.V. Pavlishchuk, A. W. Addison, Inorganica Chimica Acta, 2000, 298, 97-102

23. C. Iojoiu, P. Genova-Dimitrova, M. Marechal, J-Y. Sanchez, Electrochim. Acta 2006, 51(23), 4789 .

24. J.-Y. Sanchez, F. Chabert, C. Iojoiu, J. Salomon, N. El Kissi, Y. Piffard, M. Marechal, H. Galiano, R. Mercier, Electrochim. Acta 2007, 53(4), 1584. 
25. R. E. Ramìrez, L. C. Torres-González, E. M. Sanchez, J. Electrochem. Soc., 2007, 154 (2), B229.

26. A. S. Larsen, J. D. Holbrey, F. S. Tham, C. A. Reed, J. Am. Chem. Soc., 2000, 122, 7264.

27. H. Tokuda, K. Ishii, M. A. B. H. Susan, S. Tsuzuki, K. Hayamizu, M. Watanabe, J. Phys. Chem. B, 2006, 110, 2833.

28. A. Noda, M. Abu Bin Hasan Susan, K. Kudo, S. Mitsushima, K. Hayamizu, M. Watanabe, J. Phys. Chem. B, 2003, 107, 4024.

29. G. Horanyi, Electrochimica Acta, 1990, 35 (6) 919.

30. Y. Matsuda, H. Tamura, Electrochimica Acta, 1969, 14, 427.

31. A. Martinelli, A. Matic, P. Jacobsson, L. Boerjesson, A. Fernicola, S. Panero, B. Scrosati, H. Ohno, J. Phys. Chem. B, 2007, 111, 12462. 


\section{Figure and table captions.}

Table 1. PCILs physical characteristics.

Table 2. Self diffusion coefficients, transference numbers $\left(\mathrm{T}^{+}\right)$, NMR calculated conductivities $\left(\sigma_{\text {calc }}\right)$, and dissociation for some CLIPs at $130^{\circ} \mathrm{C}$.

Table 3. Viscosities, conductivities and self diffusion coefficients of blends of $\mathbf{6}$ (TF-TEA) and water.

Figure 1: Inter and intra-molecular hydrogen bonding involved in half neutralized diamines.

Figure 2: Conductivity vs recriprocal temperature a) monoammonium based PCIL (15), b) half neutralized diamine based PCIL (24)

Figure 3: Self diffusion coefficients of $\mathbf{1 6}$ and $\mathbf{2 4 .}$

Figure 4: Transference numbers vs temperature for monoammonium based CLIP (15), and half neutralized diamine based PCIL (24)

Figure 5: Cyclic voltammetry on platinum electrode (diam. $5 \mathrm{~mm}$ ) of monoamines involved in PCIL's $(2 \mathrm{mM})$ in $\mathrm{CH}_{3} \mathrm{CN}+0.1 \mathrm{M}$ TBAP, $\mathrm{v}=100 \mathrm{mV} \cdot \mathrm{s}^{-1}$.

Figure 6: Cyclic voltammetry on platinum electrode (diam. $5 \mathrm{~mm}$ ) of monammonium based PCIL's (2 mM) involving monoamines in $\mathrm{CH}_{3} \mathrm{CN}+0.1 \mathrm{M}$ TBAP, $\mathrm{v}=100 \mathrm{mV} \cdot \mathrm{s}^{-1}$.

Figure 7: $\mathrm{CV}$ of 2 millimolar DAPr-TF (24) in $\mathrm{CH}_{3} \mathrm{CN}+0.1 \mathrm{M}$ TBAP on platinum electrode (diam. $5 \mathrm{~mm}), \mathrm{v}=100 \mathrm{mV} \cdot \mathrm{s}^{-1}$.

Figure 8: Storage modulus vs temperature of Nafion neutralized by mono and diamines. 
Table 1.

\begin{tabular}{|c|c|c|c|c|c|c|c|}
\hline Amine & issue & PCIL code & $\mathbf{T}_{\mathbf{m}}\left({ }^{\circ} \mathbf{C}\right)$ & $\begin{array}{l}\mathbf{T}_{\text {deg }} \\
\left({ }^{\circ} \mathbf{C}\right)\end{array}$ & $\begin{array}{l}\text { density } \\
\left(130^{\circ} \mathrm{C}\right)\end{array}$ & $\begin{array}{c}\eta \text { at } 130^{\circ} \mathrm{C} \\
(\mathrm{mPa} . \mathrm{s})\end{array}$ & $\begin{array}{c}\sigma(\mathrm{mS} / \mathrm{cm}) \\
\text { at } 130^{\circ}\end{array}$ \\
\hline$\left(\mathrm{CH}_{3}\right)_{2} \mathrm{NH}$ & 1 & DMA-TF & 114 & 390 & $\mathrm{~b}$ & $\mathrm{~b}$ & $\mathrm{c}$ \\
\hline$\left(\mathrm{CH}_{3}\right)_{3} \mathrm{~N}$ & 2 & TMA-TF & 150 & 380 & $\mathrm{~b}$ & $\mathrm{~b}$ & $\mathrm{c}$ \\
\hline $\mathrm{C}_{2} \mathrm{H}_{5} \mathrm{NH}_{2}$ & 3 & EA-TF & 173 & 400 & $\mathrm{~b}$ & $\mathrm{a}$ & c \\
\hline$\left(\mathrm{C}_{2} \mathrm{H}_{5}\right)_{2} \mathrm{NH}$ & 4 & DEA-TF & 127 & 390 & $\mathrm{~b}$ & 6 & $\mathrm{~d}$ \\
\hline$\left(\mathrm{CH}_{3}\right)_{2} \mathrm{CHNH}_{2}$ & 5 & isPr-TF & 180 & 395 & $\mathrm{~b}$ & $\mathrm{~b}$ & $\mathrm{c}$ \\
\hline$\left(\mathrm{C}_{2} \mathrm{H}_{5}\right)_{3} \mathrm{~N}$ & 6 & TEA-TF & 36 & 380 & 1.33 & 14 & 31 \\
\hline $\mathrm{CH}_{3} \mathrm{CH}_{2} \mathrm{CH}_{2} \mathrm{NH}_{2}$ & 7 & PrA-TF & 176 & 385 & $\mathrm{~b}$ & $\mathrm{~b}$ & $\mathrm{c}$ \\
\hline$\left(\mathrm{C}_{3} \mathrm{H}_{7}\right)_{2} \mathrm{NH}$ & 8 & DPrA-TF & 136 & 390 & $\mathrm{~b}$ & 7 & $\mathrm{c}$ \\
\hline$\left(\mathrm{C}_{3} \mathrm{H}_{7}\right)_{3} \mathrm{~N}$ & 9 & TPrA-TF & 160 & 380 & $\mathrm{~b}$ & $\mathrm{~b}$ & $\mathrm{c}$ \\
\hline $\mathrm{CH}_{3}\left(\mathrm{CH}_{2}\right)_{3} \mathrm{NH}_{2}$ & 10 & $\mathrm{BuA}-\mathrm{TF}$ & 178 & 380 & $\mathrm{~b}$ & $\mathrm{~b}$ & c \\
\hline$\left(\mathrm{C}_{4} \mathrm{H}_{9}\right)_{3} \mathrm{~N}$ & 11 & TBuA-TF & 128 & 383 & $\mathrm{~b}$ & $\mathrm{~d}$ & $\mathrm{c}$ \\
\hline$\left(\mathrm{C}_{4} \mathrm{H}_{9}\right)_{2} \mathrm{NH}$ & 12 & DBuA-TF & 140 & 390 & $\mathrm{~b}$ & $\mathrm{~b}$ & $\mathrm{c}$ \\
\hline$\left(\mathrm{C}_{2} \mathrm{H}_{4}-\mathrm{O}-\mathrm{CH}_{3}\right)_{2} \mathrm{NH}$ & 13 & BMEA-TF & 55 & 300 & 1.41 & 6 & 27 \\
\hline $\mathrm{CH}_{3}-\mathrm{CH}_{2}-\mathrm{NH}-\mathrm{CH}_{3}$ & 14 & EtMA-TF & 90 & 385 & 1.62 & 3.79 & 50 \\
\hline $\mathrm{CH}_{3}-\left(\mathrm{CH}_{2}\right)_{3}-\mathrm{NH}-\mathrm{CH}_{3}$ & 15 & MBuA-TF & 70 & 380 & 1.45 & 4.16 & 30 \\
\hline \multirow[t]{5}{*}{$\mathrm{CH}_{3}-\left(\mathrm{CH}_{2}\right)_{3}-\mathrm{NH}-\mathrm{CH}_{2}-\mathrm{CH}_{3}$} & 16 & EtBuA-TF & 78 & 390 & 1.30 & 5.13 & 23 \\
\hline & 17 & Py-TF & 157 & 395 & $\mathrm{~b}$ & $\mathrm{~b}$ & $\mathrm{c}$ \\
\hline & 18 & MetPy-TF & 103 & 382 & $\mathrm{~b}$ & $\mathrm{~d}$ & 30 \\
\hline & 19 & BuPy-TF & 6 & 390 & 1.30 & 4.9 & 32 \\
\hline & 20 & Pir-TF & 145 & 390 & $\mathrm{~b}$ & $\mathrm{~b}$ & $\mathrm{c}$ \\
\hline
\end{tabular}




\section{Page 33 of 44}

\section{Fuel Cells}

\begin{tabular}{|c|c|c|c|c|c|c|c|}
\hline & $\mathbf{2 1}$ & MetPir-TF & 101 & 380 & $\mathrm{~b}$ & $\mathrm{~d}$ & 28 \\
\hline $\mathrm{N}$ & $\mathbf{2 2}$ & EtPir-TF & 59 & 382 & $\mathrm{~d}$ & $\mathrm{~d}$ & 30 \\
\hline $\mathrm{CH}_{2} \mathrm{H}_{5}$ & $\mathbf{2 3}$ & EtMph-Tf & 44 & 375 & $\mathrm{~d}$ & $\mathrm{~d}$ & 27 \\
\hline $\mathrm{N}-\mathrm{C}_{2} \mathrm{H}_{5}$ & & & & & & & 35 \\
\hline $\mathrm{NH}_{2}-\left(\mathrm{CH}_{2}\right)_{2}-\mathrm{NH}_{2}$ & $\mathbf{2 4}$ & DAEt-TF & 78 & 240 & 1.60 & 27 & 45 \\
\hline $\mathrm{NH}_{2}-\left(\mathrm{CH}_{2}\right)_{3}-\mathrm{NH}_{2}$ & $\mathbf{2 5}$ & DAPr-TF & 36 & 260 & 1.60 & 40 & 7 \\
\hline $\mathrm{NH}_{2}-\left(\mathrm{CH}_{2}\right)_{10}-\mathrm{NH}_{2}$ & $\mathbf{2 6}$ & DAD-TF & 49 & 250 & 1.22 & 81 & 7 \\
\hline
\end{tabular}

a: cannot be determined due to the high crystalline character ; b: too high melting point to be investigated ;

c: $\sigma$ less than $10^{-3} \mathrm{mS} . \mathrm{cm}^{-1}$; d: not carried out. 
Table 2.

\begin{tabular}{|l|c|c|c|c|c|c|c|}
\hline \multicolumn{1}{|c|}{$\begin{array}{c}\text { Sample } \\
\text { code }\end{array}$} & $\begin{array}{c}\mathbf{D}_{\mathbf{H}+} \\
\left(\mathbf{c m}^{2} \mathbf{s}^{-\mathbf{1}}\right)\end{array}$ & $\begin{array}{c}\mathbf{D}_{\mathbf{a m}} \\
\left(\mathbf{c m}^{\mathbf{2}} \mathbf{s}^{-\mathbf{1}}\right)\end{array}$ & $\begin{array}{c}\mathbf{D}_{\text {anion }} \\
\left(\mathbf{c m}^{\mathbf{2}} \mathbf{s}^{-\mathbf{1}}\right)\end{array}$ & $\mathbf{T}^{+}$ & $\begin{array}{c}\sigma_{\text {calc }} \\
\left(\mathbf{S c m}^{-\mathbf{1}}\right)\end{array}$ & $\begin{array}{c}\sigma_{\text {exp }} \\
\left(\mathbf{S c m}^{-\mathbf{1}}\right)\end{array}$ & $\begin{array}{c}\text { Dissociation } \\
\text { rate }\end{array}$ \\
\hline $\mathbf{6}$ (TEA-TF) & $3.9 \times 10^{-6}$ & $3.6 \times 10^{-6}$ & $3.0 \times 10^{-6}$ & 0.56 & 0.1 & 0.030 & 0.30 \\
\hline $\mathbf{1 3}$ (BMEA-TF) & $2.0 \times 10^{-6}$ & $2.2 \times 10^{-6}$ & $2.2 \times 10^{-6}$ & 0.49 & 0.067 & 0.027 & 0.40 \\
\hline $\mathbf{2 4}$ (DAE-TF) & $1.90 \times 10^{-6}$ & $1.36 \times 10^{-6}$ & $1.18 \times 10^{-6}$ & 0.51 & - & 0.035 & - \\
\hline $\mathbf{2 5}$ (DAPr-TF) & $4.50 \times 10^{-6}$ & $3.85 \times 10^{-6}$ & $3.13 \times 10^{-6}$ & 0.58 & - & 0.046 & - \\
\hline $\mathbf{1 4}$ (BuMA-TF) & $3.77 \times 10^{-6}$ & $3.767 \times 10^{-6}$ & $3.71 \times 10^{-6}$ & 0.5 & 0.067 & 0.016 & 0.24 \\
\hline $\mathbf{1 5}$ (BuEtA-TF) & $2.97 \times 10^{-6}$ & $2.94 \times 10^{-6}$ & $2.93 \times 10^{-6}$ & 0.5 & 0.058 & 0.015 & 0.26 \\
\hline
\end{tabular}


Table 3.

\begin{tabular}{|c|c|c|c|c|c|c|c|c|c|c|c|c|}
\hline \multirow{3}{*}{$\begin{array}{l}\text { x/y } \\
\mathrm{mol} / \mathrm{mol} \\
0\end{array}$} & \multicolumn{2}{|c|}{$\begin{array}{c}\eta \\
(\mathbf{m P a} . s)\end{array}$} & \multicolumn{2}{|c|}{$\sigma(\mathrm{mS} / \mathrm{cm})$} & \multirow{2}{*}{\multicolumn{2}{|c|}{$\begin{array}{c}\mathrm{D}_{\mathrm{am}} \\
\left(\mathrm{cm}^{2} \mathrm{~s}^{-1}\right) \\
\times \mathbf{1 0}^{-6}\end{array}$}} & \multirow{2}{*}{\multicolumn{2}{|c|}{$\begin{array}{c}\mathrm{D}_{\mathrm{H}+} \\
\left(\mathrm{cm}^{2} \mathrm{~s}^{-1}\right) \\
\times 10^{-6}\end{array}$}} & \multirow{2}{*}{\multicolumn{2}{|c|}{$\begin{array}{c}D_{\text {anion }} \\
\left(\mathrm{cm}^{2} \mathrm{~s}^{-1}\right) \\
\times 10^{-6}\end{array}$}} & \multirow{2}{*}{\multicolumn{2}{|c|}{$\begin{array}{c}D_{\mathrm{H} 2 \mathrm{O}} \\
\left(\mathrm{cm}^{2} \mathrm{~s}^{-1}\right) \\
\times 10^{-6}\end{array}$}} \\
\hline & $40^{\circ} \mathrm{C}$ & $30^{\circ} \mathrm{C}$ & $40^{\circ} \mathrm{C}$ & $80^{\circ} \mathrm{C}$ & & & & & & & & \\
\hline & 36 & 16 & 10 & 20 & 0.28 & 1.20 & 0.28 & 1.20 & 0.22 & 1 & $\mathrm{a}$ & $\mathrm{a}$ \\
\hline $1 / 10$ & 34 & 13 & 11 & 23 & 0.50 & 2.40 & 0.50 & 8.40 & 0.45 & 2.20 & 3.45 & 19 \\
\hline $1 / 5$ & 33 & 12 & 12 & 24 & $\mathrm{c}$ & $\mathrm{c}$ & $\mathrm{c}$ & $\mathrm{c}$ & $\mathrm{c}$ & $\mathrm{c}$ & $\mathrm{c}$ & $\mathrm{c}$ \\
\hline $1 / 2$ & 31 & 12 & 14 & 26 & 0.80 & 4.20 & $\mathrm{~b}$ & $\mathrm{~b}$ & 0.70 & 3.60 & $\mathrm{~b}$ & $\mathrm{~b}$ \\
\hline $1 / 1$ & 21 & 10 & 17 & 30 & .88 & 5.40 & 6.50 & $\mathrm{~b}$ & 0.88 & 5.44 & 5.50 & $\mathrm{~b}$ \\
\hline
\end{tabular}

a: anhydrous PCIL, b: not possible to measure (peak to large) c: not carried out 

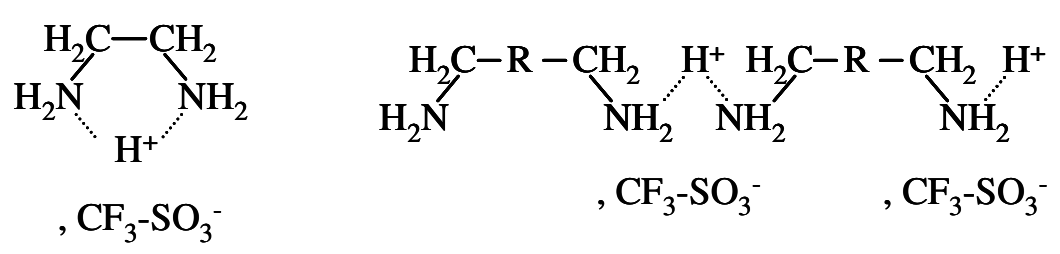

Figure 1 


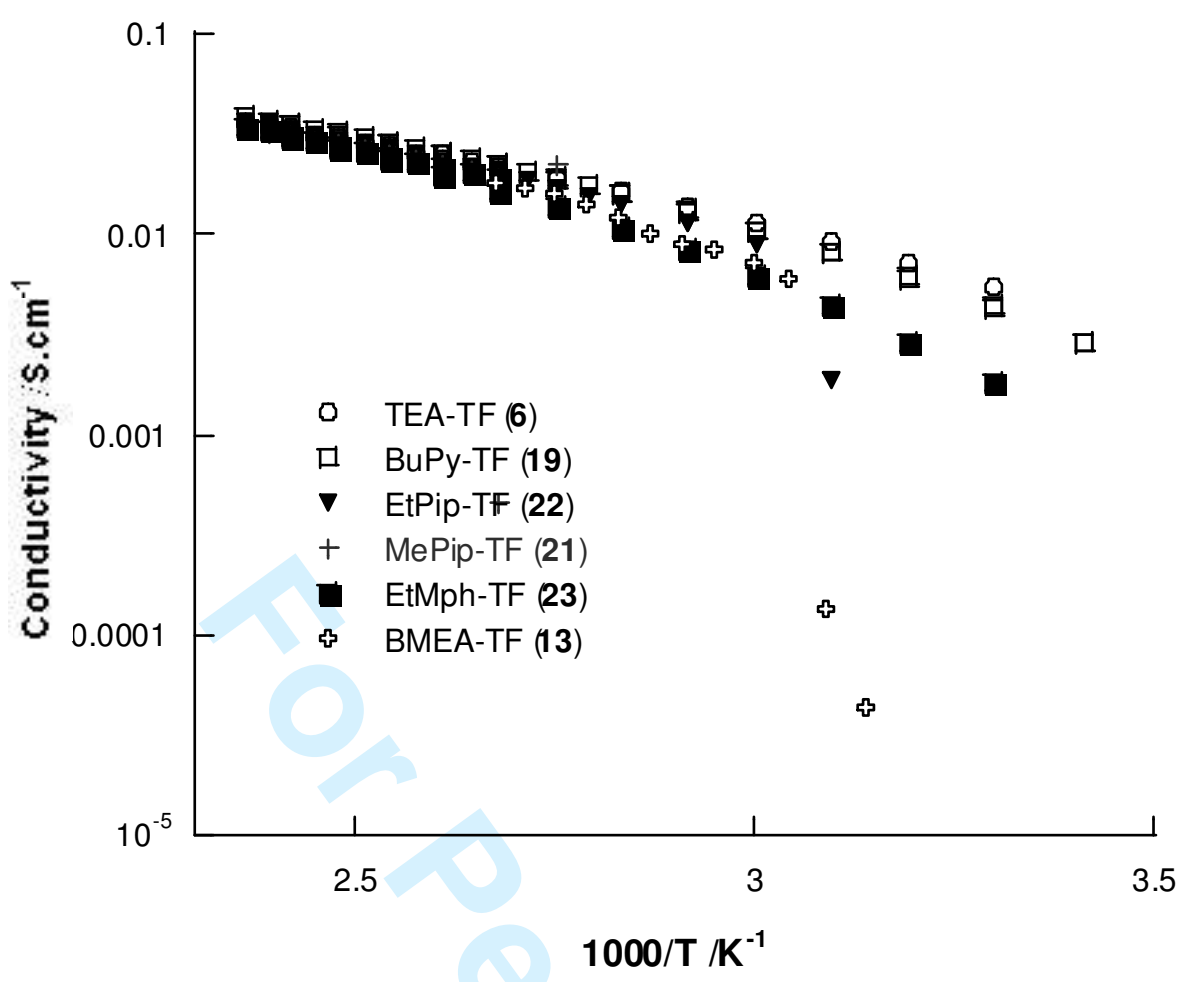

a

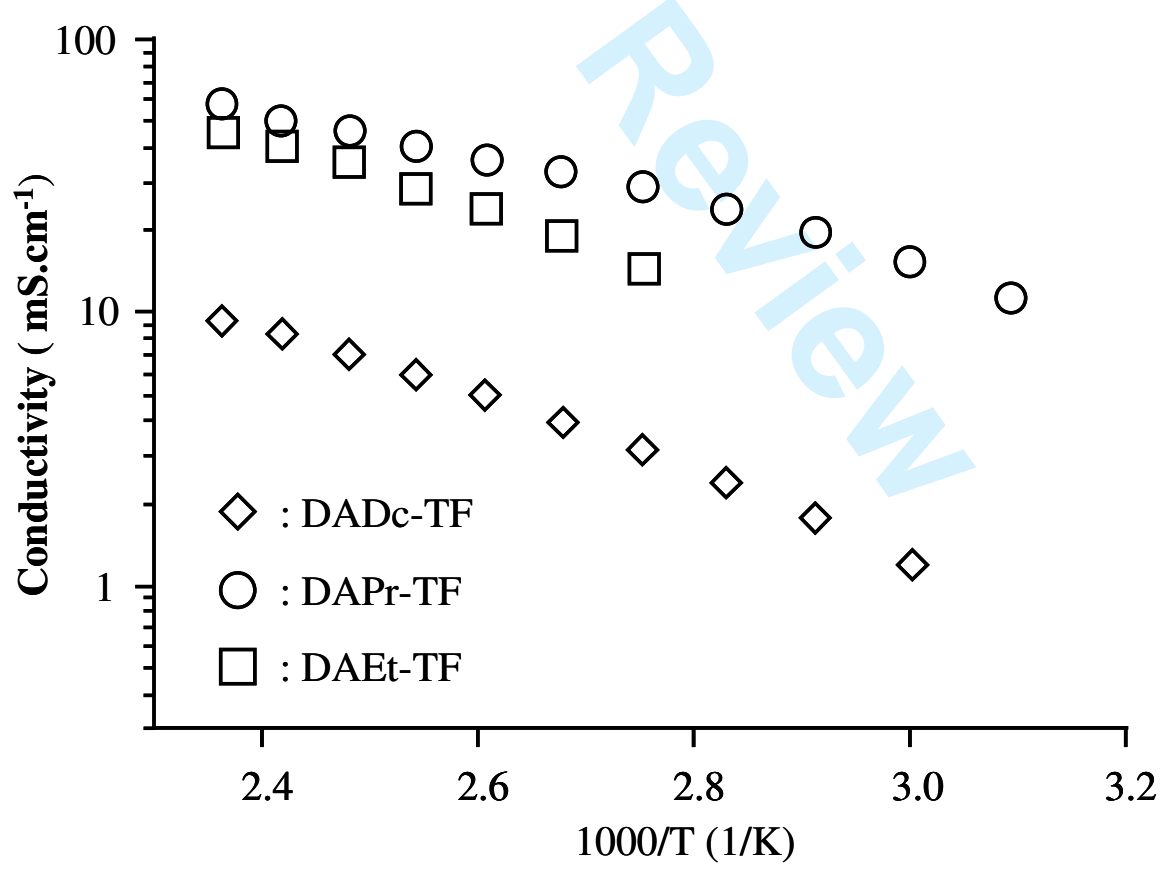

b)

Figure 2 

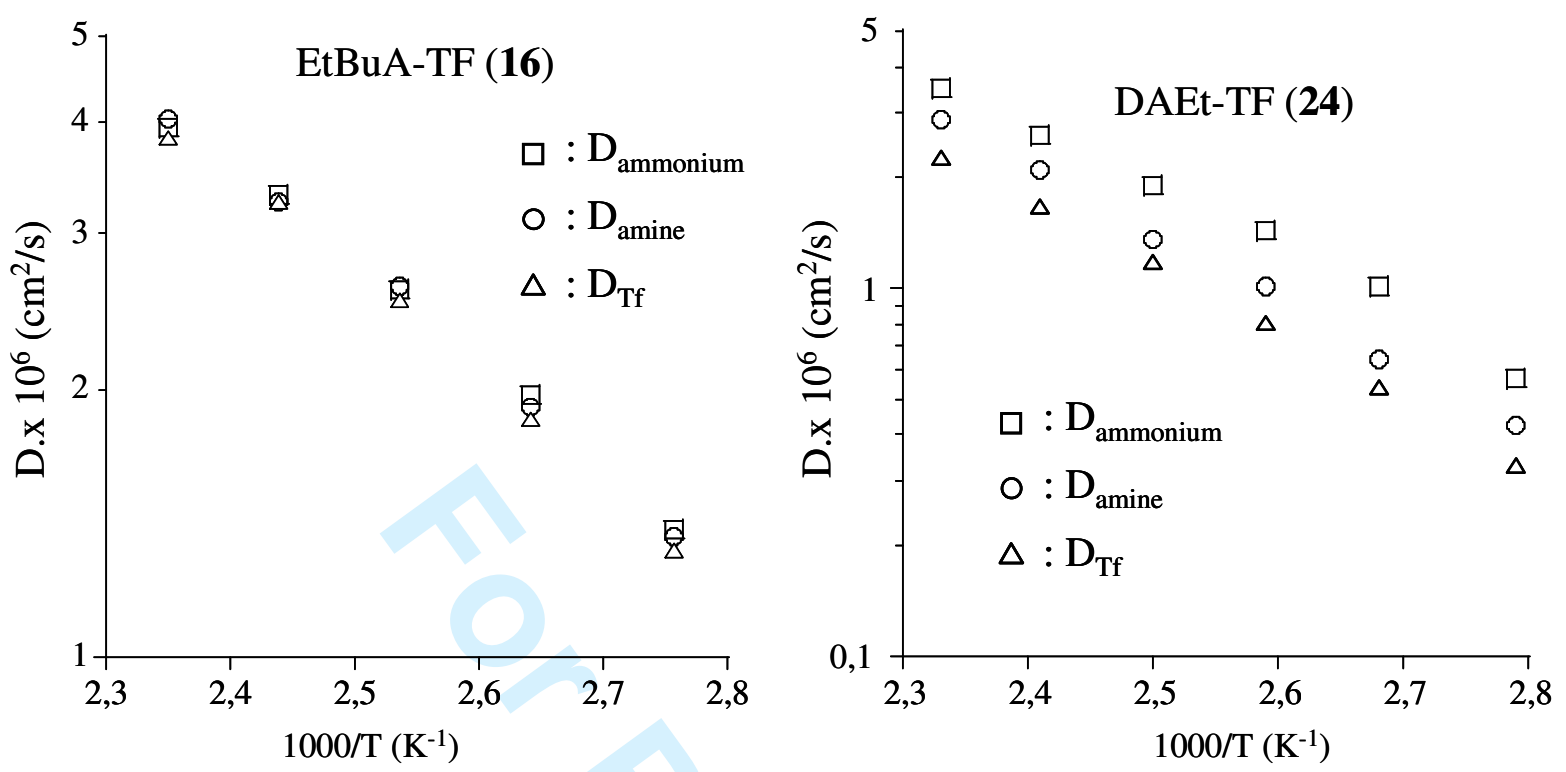

Figure 3 


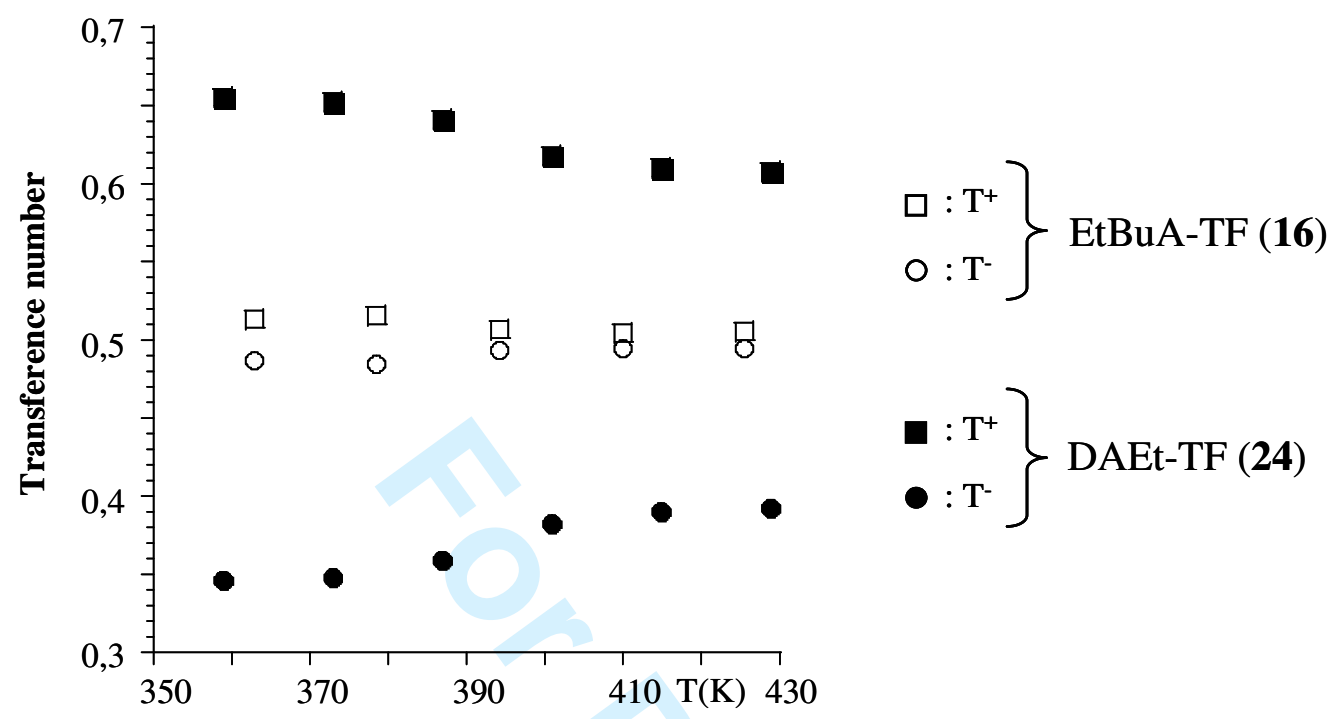

Figure 4 


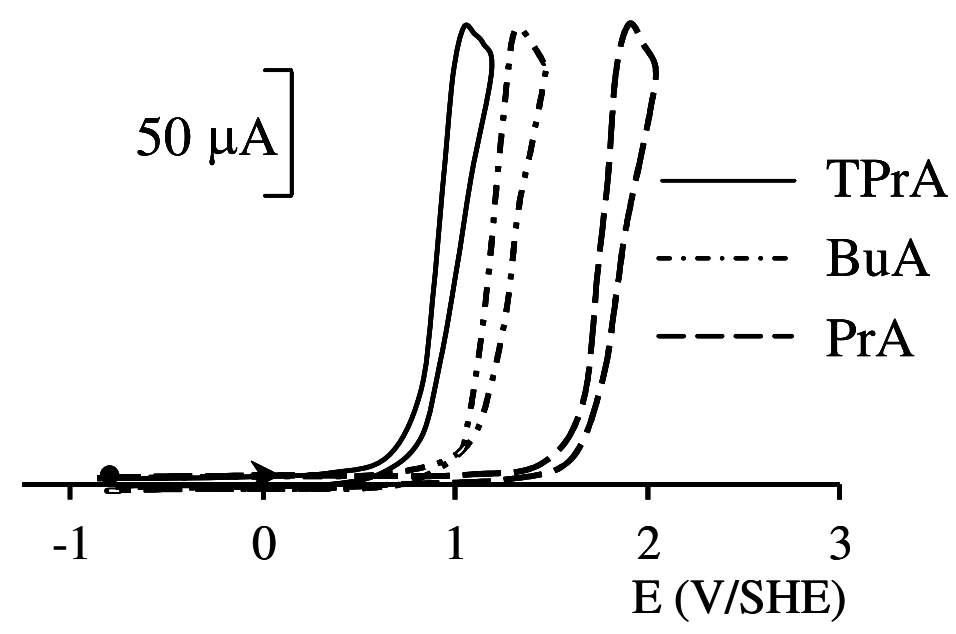

Figure 5 
Figure 6 


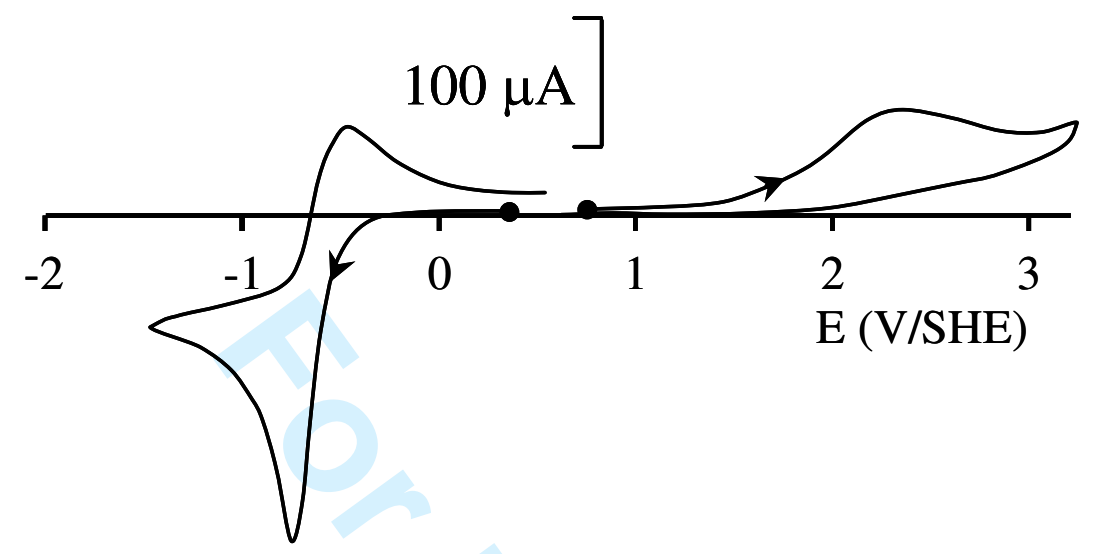

Figure 7 


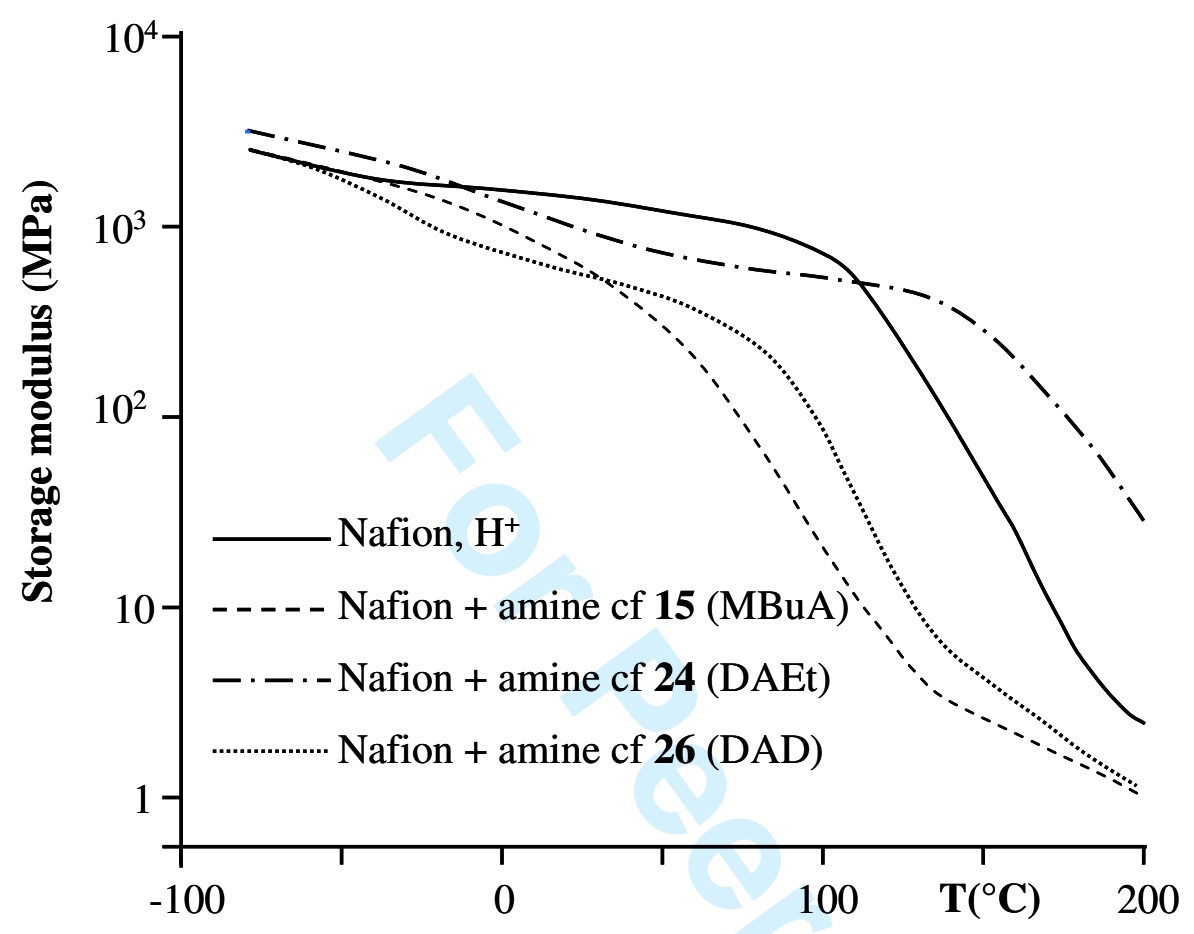

Figure 8. 